\title{
LA DEFENSA EXTRAJUDICIAL DE LA POSESIÓN: UN
}

\section{ANÁLISIS IMPOSTERGABLE}

\author{
José Luis Ticona Yanqui *
}

\section{INFORMACIÓN DEL ARTÍCULO}

Art. Recibido: $30 / 06 / 2020$

Art. Aceptado: 04/08/2020

Art. Publicado: 10/08/2020 


\title{
RESUMEN:
}

La finalidad del presente trabajo, de carácter eminentemente cualitativo, es analizar la institución jurídica civil de la defensa extrajudicial de la posesión en el país, considerando a la misma como un método de autocomposición de conflictos de posesión, incidiendo en su importancia como herramienta de solución de conflictos de intereses particulares y de disipar incertidumbres jurídicas. La metodología utilizada es básicamente de carácter descriptiva - explicativa y exegética, pues se analiza la evolución de la legislación peruana respecto a la defensa extrajudicial de la posesión. Los comentarios y resultados obtenidos nos permiten concluir que la actual norma que regula la defensa extrajudicial de la posesión no es coherente con los hechos que se van presentado en la realidad social, lo que resulta preocupante, porque nos permite percibir que las normas civiles peruanas se están regulando no considerando las expectativas de la sociedad y las graves consecuencias jurídicas que las mismas podrían generar.

Palabras Claves: Posesión, Propiedad, Defensa de la posesión, Edificación, Plazos legales, Conflictos.

\section{THE EXTRAJUDICIAL DEFENSE OF POSSESSION: AN URGENT ANALYSIS}

\begin{abstract}
:
The purpose of this work, of an eminently qualitative nature, is to analyse the civil legal institution of the extrajudicial legal institution of possession in the country, considering it as a method of self-composition of conflicts of possession, influencing its importance as a tool for the settlement of conflicts of particular interests and dispeling legal uncertainties. The methodology used is basically descriptive - explanatory and exestic, because it analyses the evolution of Peruvian legislation with regard to the extrajudicial defense of possession. The comments and results obtained allow us to conclude that the current rule governing the extrajudicial defense of possession is not consistent with the facts that are presented in the social reality, which is worrying, because it allows us to perceive that Peruvian civil rules are being regulated not taking into consideration the expectations of society and the serious legal consequences that they couldgenerate.
\end{abstract}

Keywords: Property, Defense of possessión, Building, Legal terms, Conflicts. 


\section{INTRODUCCIÓN:}

Hace muchos años atrás uno de los pilares del Derecho y creador de la Escuela Histórica del Derecho, Friedrich Karl von Savigny (21-02-1779 / 25-10-1861), daba a conocer al mundo su famosa obra "Derecho de la Posesión" (1803), en dicho trabajo de manera coherente explico y sustento su famosa teoría subjetiva de la posesión y el estudio de textos romanos sobre la materia, buscando el verdadero sentido que los autores habían dado a la institución de la posesión. El pensamiento y la teoría de Savigny fue objeto de revisión y crítica por parte de uno de sus discípulos más importantes Caspar Rudolf von Ihering (22-08-1818 / 17-09-1892), quien en su trabajo "La voluntad en la posesión: crítica del método jurídico reinante" (1889), despliega su famosa teoría objetiva de la posesión, teoría que adopta nuestro Código Civil de 1984 y la mayoría de código civiles del mundo, sin embargo, es bueno precisar que también en dicho cuerpo legal normativo civil aparece la teoría subjetiva, específicamente en el tema de la prescripción adquisitiva de dominio.

Nuestro Código Civil regula la defensa extrajudicial de la posesión en el artículo 920, el que tiene un nuevo texto a partir de la dación de la Ley Nro. 30230 - Ley que establece medidas tributarias, simplificación de procedimientos y permisos para la promoción y dinamización de la inversión en el país -, publicada en el Diario Oficial "El Peruano" en fecha 12 de julio del año 2014; a través del presente artículo se hace una análisis descriptivo y explicativo de dicha norma, incidiendo en su utilidad y practicidad para resolver conflictos de intereses y eliminar incertidumbres jurídicas referidos a temas de la defensa extrajudicial de la posesión, es así, que tal análisis, inclusive exegético se realiza a los cuatro párrafos que contienen la norma civil aludida, sobre todo verificando la utilidad de las mismas en la resolución de casos prácticos, para ello se recurre a la interpretación de la ley y las fuentes de la doctrina, abocándonos a comentar e interpretar mediante el uso de recursos cualitativos del análisis y la interpretación, todo ello para hacer efectivo los derechos sustanciales de las personas y lograr su finalidad abstracta que es la paz social en justicia.

Al final del trabajo se formulan conclusiones que permiten verificar la importancia del mismo, su relevancia e interés que tienden a sustraer la problemática verificada en la redacción del artículo 920 del Código Civil.

\section{MATERIALES Y MÉTODOS:}

El trabajo está enmarcado dentro de un tipo de investigación cualitativa, sin dejar de tener un carácter científico, dogmático, analítico e interpretativo. Por lo que su contenido metodológico es:

ANALÍTICO: Mediante este método, que permite realizar una profundización de las esencias del contenido dogmático, y trata de entender su sentido semántico de manera amplia y rigurosa, se analiza e interpreta correctamente la institución de la defensa extrajudicial de la posesión, sustentada la misma en una correcta argumentación de sus contenidos.

INTERPRETACIÓN: Desde el enfoque de la argumentación e interpretación jurídica, mediante la interpretación se encuentra las claves del proceso de análisis de la exegesis que se trata de comprender en forma amplia y rigurosa. No debe olvidarse que una interpretación sistemática garantiza la ampliación y precisión de la interpretación que incide en una mejor y sostenida argumentación. 
Journal homepage: http://revistas.unap.edu.pe/rd/ E-mail: revistaderecho@unap.edu.pe

\section{DISCUSIÓN Y RESULTADOS:}

\subsection{EVOLUCIÓN HISTÓRICA DEL ARTÍCULO 920 DEL CÓDIGO CIVIL:}

En el Código Civil de 1852, no se regulo de manera expresa la institución de la defensa extrajudicial de la posesión, sin embargo, meridianamente fue reconocida en los términos siguientes:

Artículo 470: El poseedor goza de los derechos siguientes: ...2. No está obligado a responder de la cosa, en juicio sumario, sino en ordinario, cuando la ha poseído por más de un año; 3. No debe ser desposeído de la cosa, si antes no ha sido citado, oído y vencido en juicio...

Mientras que el Código Civil de 1936 si regulo la institución jurídica de la defensa extrajudicial, disponiendo:

Artículo 830: El poseedor puede repeler la fuerza que se emplee contra él y recobrar el bien sin intervalo de tiempo, si fue desposeído; pero, en ambos casos, deberá abstenerse de las vías de hecho no justificadas por las circunstancias.

Ahora bien, la redacción primigenia del artículo 920 del Código Civil de 1984 fue en los términos siguientes:

Artículo 920: El poseedor puede repeler la fuerza que se emplee contra él y recobrar el bien, sin intervalo de tiempo, si fuere desposeído, pero en ambos casos debe abstenerse de las vías de hecho no justificadas por las circunstancias.

Este artículo fue modificado por el artículo 67 de la Ley Nro. 30230 - Ley que establece medidas tributarias, simplificación de procedimientos y permisos para la promoción y dinamización de la inversión en el país -, publicada en el Diario Oficial "El Peruano" en fecha 12 de julio del año 2014, en la forma detallada:

Artículo 920: El poseedor puede repeler la fuerza que se emplee contra él o el bien y recobrarlo, si fuere desposeído. La acción se realiza dentro de los quince (15) días siguientes a que tome conocimiento de la desposesión. En cualquier caso, debe abstenerse de las vías de hecho no justificadas por las circunstancias.

El propietario de un inmueble que no tenga edificación o esta se encuentre en dicho proceso, puede invocar también la defensa señalada en el párrafo anterior en caso de que su inmueble fuera ocupado por un poseedor precario. En ningún caso procede la defensa posesoria si el poseedor precario ha usufructuado el bien como propietario por lo menos diez (10) años.

La Policía Nacional del Perú, así como las Municipalidades respectivas, en el marco de sus competencias previstas en la Ley Orgánica de Municipalidades, deben prestar el apoyo necesario a efectos de garantizar el estricto cumplimiento del presente artículo, bajo responsabilidad.

En ningún caso procede la defensa posesoria contra el propietario de un inmueble, salvo que haya operado la prescripción, regulada en el Artículo 950 de este Código.

A la fecha se tiene presentado un Anteproyecto de Reforma del Código

Civil Peruano de 1984, el mismo que fue entregado al Ministerio de Justicia y Derechos Humanos, por parte del Grupo de Trabajo de Revisión y Mejora del Código Civil, constituida por la Resolución Ministerial Nro. 0300-2016-JUS, producto de una labor poco más de dos años y en la que intervinieron más de 60 juristas nacionales; es así, que en este proyecto se propone se modifique el artículo en comentario en los términos siguientes:

Artículo 920: El poseedor puede repeler la fuerza que se emplee contra su posesión y recobrar el bien, sin intervalo de tiempo, si fuere desposeído, pero en ambos casos debe abstenerse de las vías de hecho no justificadas por las circunstancias. 
Journal homepage: http://revistas.unap.edu.pe/rd/ E-mail: revistaderecho@unap.edu.pe

\subsection{CONCEPTO DE POSESIÓN:}

Antes de dar un concepto de posesión debemos tener en cuenta que la posesión es el más antiguo de todos los derechos reales, su origen histórico, pudo haber sido en la aprehensión en los bienes muebles y la ocupación de los bienes inmuebles, todos, debe entenderse, adquiridos por la fuerza; ambas constituyeron, desde entonces, un derecho.

El profesor CUADROS VILLENA (1996) afirma:

La posesión es el aprovechamiento directo, de hecho, o de derecho, del valor de uso o disfrute de una cosa. Esta definición encierra los siguientes elementos: a) La realización objetiva del hombre con las cosas; b) La utilización del valor económico de las cosas en cuanto sirven para el uso o disfrute, es la utilización del valor de uno incorporado en las cosas; c) Comprende dos clases de posesión: La que nace del poder de hecho sobre las cosas, sin título, por mera voluntad del poseedor, y la que nace del derecho de propiedad, como una de las facultades del propietario. La primera es la posesión estimada como instituto autónomo, y la segunda, la posesión derivada del derecho de propiedad. (p. 278).

A su turno el profesor GONZALES LINARES (2012) precisa:

La posesión, en sentido estricto, es la presencia de un conjunto de actos materiales de contenido económico, y como tal una situación fáctica con trascendencia jurídica y social. Nuestra percepción jurídica sobre el instituto de la posesión, la podemos transmitir definiéndola como el derecho real que establece una relación directa y efectiva del poseedor con los bienes (relaciones reales), con el objeto de obtener beneficios de su utilidad económica. Tratada con autonomía científica y legislativa frente a la propiedad. (p.p. 174-175).

RAMIREZ CRUZ (2017) anota:

La posesión, en resumidas cuentas, el derecho real que establece una relación directa e inmediata de dominación exclusiva (uso y goce, o sea, aprovechamiento económico) entre una persona y un bien, con autonomía y prescindencia de la titularidad (derecho) a ella. Es un derecho de carácter provisional. Esta es la posesión de hecho, aquella que carece de título justificativo... En realidad, la postura que defiende a la posesión como un puro hecho (y que la niega como derecho), no tiene mayor asidero; la misma es típica del antiguo derecho romano, al paso que el derecho moderno sólo protege la posesión fáctica en determinados supuestos. De ahí que estamos convencidos que la posesión es hoy un derecho (p. 282).

A mi criterio personal puedo precisar que "la posesión es un poder de hecho, el mismo que se materializa cuando un sujeto de manera efectiva e independiente lo ejerce sobre un determinado bien, con la finalidad de utilizarlo para su interés económico, la que es protegida por ley, prescindiéndose si corresponde o no la existencia de un derecho".

No debemos olvidar que la posesión se incorpora a nuestro mundo jurídico por primera vez en el Código Civil de 1852 sustentándose en la doctrina de Savigny. El Código Civil de 1936, se alinea dentro de la teoría de Ihering, tomando en cuenta que el mismo precisa que la posesión en todos los casos se establece en relación material voluntaria con las cosas. El concepto de posesión en el vigente Código Civil, es similar al concepto del Código Civil de 1936, es así como se regula en el artículo 896, en consecuencia, para asegurar la utilización económica del bien, debe conferirse al poseedor el derecho de usar, disfrutar y disponer del bien; por lo tanto, la posesión no es necesariamente legítima; son poseedores tanto el propietario como el ladrón, siempre que ejerzan de hecho una de las facultades del derecho de propiedad. La definición del artículo 896 del Código Civil, significa también que no basta con tener derecho a poseer, para ser poseedor hay que ejercer de hecho un poder inherente a la propiedad, aunque no se tenga derecho a tal posesión. Se puede tener derecho a 


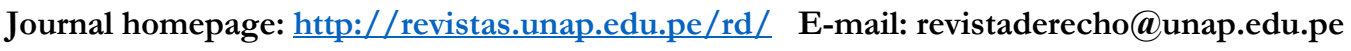

la posesión, pero si no se ejerce de hecho un atributo de la propiedad, no se puede reputar al mismo poseedor.
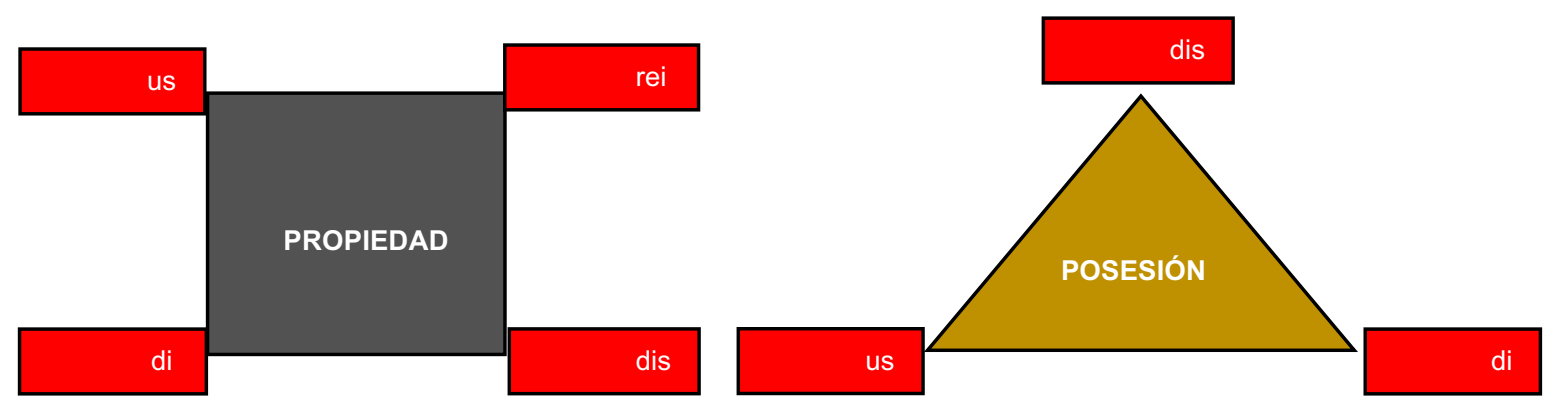

\subsection{DEFENSA DE LA POSESIÓN:}

La posesión es el ejercicio de hecho sobre un bien (tengo el bien en mi poder) - artículo 896 del Código Civil -, mientras la propiedad o cualquier otro derecho real es un poder jurídico reconocido por la ley (tengo un título) - artículo 923 del Código Civil -. Esta tutela no significa una protección de la posesión como si ésta fuese un "ius", sino como lo que es realmente: un "factum", es decir, un hecho cierto y visible "prima facie", el cual es objeto de una protección interina en tanto se trata de una situación comprobable en forma inmediata; en cambio, la tutela del "jus" exige acreditar una relación no visible (ideal), esto es, una "titularidad jurídica" existente sólo en el mundo de la abstracción de los derechos subjetivos; por ello, la protección del "ius" sólo opera en un plano definitivo en el que se demuestre la existencia de un derecho superior frente a la sola posesión; un elemental buen sentido, exige que antes de consentir en una modificación de lo que "es" (posesión), se debe previamente demostrar lo que "debe ser" (derecho); la posesión no se tutela por ser un derecho, que no lo es, sino porque comprobado el hecho posesorio, no es el poseedor quien debe dar razón de su derecho, sino aquel que manifiesta lo contrario, esto es, quien afirma que la posesión se realiza sin derecho o que tiene un mejor derecho a poseer.

El artículo 920 del Código Civil se refiere a la defensa extrajudicial de la posesión, y, el artículo 921 del mismo cuerpo normativo civil a la defensa judicial. En el presente trabajo realizaré un análisis de la defensa extrajudicial de la posesión.

\subsection{DEFENSA EXTRAJUDICIAL DE LA POSESIÓN:}

Es bueno considerar que dentro de toda sociedad civilizada no es pertinente hacer justicia por mano propia, no rememoramos las épocas primitivas en el desarrollo de la civilización, sin embargo, como una excepción a esta regla general de convivencia viene a ser la defensa extrajudicial de la posesión, la que podemos representar como aquella conducta por el cual a un poseedor (no importa sea legitimo o ilegitimo) sin autorización de un ente judicial le arrebatan la posesión inmediata que ejerce sobre un bien por tanto está autorizado a repeler esa fuerza y recuperar el bien que le fuera arrebatado, sin embargo, es bueno considerar que estos hechos tendrían que ser realizados de una parte y de la otra parte por un solo sujeto, en caso de presentarse dos o más sujetos, estamos acaso en el limbo de la comisión de un delito. Esta forma de defesa de la posesión, algún grupo de la doctrina, denomina incorrectamente "desalojo extrajudicial". No debemos olvidar que se protege la posesión, porque 
Journal homepage: http://revistas.unap.edu.pe/rd/ E-mail: revistaderecho@unap.edu.pe

se tiene muy en cuenta que todo poseedor es reputado propietario, por eso la norma civil se preocupa por la posesión y lo considera como un mecanismo de defensa excepcional de la posesión, algún grupo de la doctrina lo considera como un mecanismo de autotutela, de acción directa, donde no se requiere el permiso del Estado como tercero para resolver un conflicto de intereses o disipar una incertidumbre. Esta acción sólo puede ser ejercida por el que tiene la calidad de poseedor. En consecuencia, como concepto preliminar podemos anotar que la defensa extrajudicial de la posesión viene a ser un método de autocomposición de conflictos de autotutela, que es una forma de auto componer conflictos de posesión sin intervención del Estado, es usar la fuerza, y el derecho valida el uso de la misma exigiendo el cumplimiento de determinados requisitos fijados por ley.

La norma vigente, difiere enormemente de la que fue derogada, ésta última era entendible, la vigente resulta muy ambigua e imprecisa, la interpretación de la norma podría tener inclusive implicancias de connotación penal, considerando que si la ley me autoriza a usar la fuerza a fin de reincorporar un bien a mi posesión, no se tiene claro hasta donde es posible el uso de tal fuerza, por tanto, si la ley me autoriza hacer uso de la fuerza debe ser muy preciso la forma y condiciones en que debo de desplegar ese derecho sin necesidad de mandato de un órgano jurisdiccional, es más, es posible lindar con el delito de contra el patrimonio en su modalidad de usurpación, la línea entre ampararse un derecho y la comisión de un delito es muy tenue.

El artículo 920 tiene cuatro partes: la primera, referida básicamente al tiempo que tiene el poseedor para poder repeler la fuerza que se emplee en contra de él; la segunda, a la defensa de un bien en edificación o que se encuentre en dicho proceso y que sólo puede formularla el propietario; la tercera parte, al apoyo que deben de prestar los efectivos de la Policía Nacional del Perú y las Municipalidades a los poseedores y los propietarios; y, la cuarta parte, a la defensa posesoria especial del propietario.

\section{a) ANÁLISIS DE LA PRIMERA PARTE:}

De una simple lectura de la primera parte del artículo 920 del Código Civil podemos inferir que en ella se encuentra la esencia de la defensa extrajudicial de la posesión materializada en el hecho de "repeler la fuerza que se emplee", considerando que la posesión se ejerce sobre los bienes y no las personas, resulta ilógico que se haya previsto "es posible repeler la fuerza que se emplee en contra del poseedor", esta aseveración podría traer una serie de interpretaciones como que cuando el poseedor es agredido con palabras irrepetibles destinadas a recuperar un bien o el uso de la fuerza leve, fuera del ámbito de ubicación del bien, podría repeler con otras palabras del mismo tono, tal vez hasta el uso de la misma fuerza leve, hechos que podría lindar con la comisión de faltas contra la persona, tal vez delitos o hasta delitos contra el honor, y en mi defensa podría argumentar "defensa extrajudicial de la posesión", en consecuencia, la norma es ambigua en tanto aparentemente permite repeler la fuerza que se emplee por parte de un tercero en contra del poseedor; sin embargo, que "el poseedor puede repeler la fuerza que se emplee contra el bien y recobrarlo" es la esencia y naturaleza de la defensa extrajudicial de la posesión, exigiendo como requisito la desposesión, considerando que sólo y sólo es posible accionar la defensa extrajudicial de la posesión una vez que el poseedor perdió la 
Journal homepage: http://revistas.unap.edu.pe/rd/ E-mail: revistaderecho@unap.edu.pe

posesión o fue despojada de la misma, en el supuesto de una "amenaza eminente de desposesión" no es posible ampararse en esta institución jurídica, debe entenderse para este tipo de casos debe hacerse valer el interdicto de retener.

Otro hecho que no puede pasar por desapercibido es que la norma autoriza al poseedor despojado de su posesión poder recobrar la misma dentro de los 15 días siguientes "a que tome conocimiento de la desposesión", no considerando dicha recuperación en el plazo más inmediato como si lo hacía la norma derogada ( 24 horas), en verdad no hay sustento alguno por que ese plazo de 15 días y porque no pudo ser 20 días u otro; esta postura relativamente es ambigua, considerando que debe entenderse que el plazo de 15 días debe de computarse a partir de "cuando el poseedor toma conocimiento de la desposesión”; es así, en el supuesto de que el poseedor no se encuentra al momento de la desposesión, por encontrarse atendiendo negocios fuera del lugar por ejemplo y llega al bien luego de 10 días, entonces tendría que computarse el plazo a partir de aquel momento (de su llegada) o desde el momento en que se produjo el despojo; sin embargo, también podría darse el supuesto de que el poseedor se encuentra en el bien y es despojado de la posesión inmediata que ejerce sobre el mismo, pero para ganar tiempo a éste no le conviene precisar que fue despojado en dicha fecha, ello con la única finalidad de resguardar celosamente el plazo de 15 días, es más, me pregunto ¿Qué medios probatorios tendría que presentar el que despojo al poseedor del bien a fin de empezar a contabilizar el plazo del poseedor?; como es sabido en la vida práctica el poseedor buscará cualquier argumento a fin de evitar que el plazo concedido por ley corra, ello a fin de mantener incólume su derecho a ejercer la defensa extrajudicial de la posesión.

De mi parte considero que no debió fijarse plazo alguno y seguir considerando la norma anterior que preveía que el plazo dentro del cual se puede repeler la fuerza que se emplee contra el bien a recobrar debe ser de manera inmediata, es más, considero que debería evitarse la postura de "si fuera desposeído" incluso ante una amenaza eminente debería ser posible usar la defensa extrajudicial de la posesión, ello con la finalidad de evitar procesos judiciales de interdictos, que para terminar con sentencia habrá que esperar un buen tiempo, como ya nos tiene acostumbrado las instancias judiciales del Poder Judicial.

\section{b) ANÁLISIS DE LA SEGUNDA PARTE:}

Este segundo párrafo es muy preocupante su redacción, considerando que autoriza sólo al "propietario" (poseedor legítimo) de un bien inmueble el uso de la defensa extrajudicial de la posesión, con la condición de que el ocupante tiene que tener la calidad de ocupante precario, pero dicha defensa extrajudicial está delimitada a dos supuestos: cuando el bien inmueble no tenga edificación o cuando dicho bien inmueble se encuentre en dicho proceso, ésta regla tiene una excepción y es que no procede la defensa posesoria cuando el poseedor precario inmediato usufructuó el bien inmueble "como propietario" por lo menos diez años, considerando que dentro de éste plazo es muy probable que este en trámite un proceso de prescripción adquisitiva de dominio ante el Poder Judicial, alguna Notaria Pública o una instancia administrativa. 
Journal homepage: http://revistas.unap.edu.pe/rd/ E-mail: revistaderecho@unap.edu.pe

A fin de realizar una correcta interpretación de esta parte de la norma analizada debemos tener claro a que debemos considerar una "edificación" o "edificación en proceso", de una revisión simple del Código Civil no encontramos un concepto de que debemos entender por edificación; sin embargo, podemos recurrir a la Ley Nro. 29090 - Ley de Regulación de Habilitaciones Urbanas y de Edificaciones - modificado por la Ley Nro. 30494, en la que se prescribe:

2. Edificación: Resultado de construir una obra sobre un predio, que cuente como mínimo con proyecto de habilitación urbana aprobado; y, cuyo destino es albergar al hombre en el desarrollo de sus actividades. Comprende las instalaciones fijas y complementarias adscritas a ella. Para efectos de la presente Ley, se considerarán las siguientes obras de edificación:

a. Edificación nueva: Aquella que se ejecuta totalmente o por etapas, sobre un terreno sin construir.

Esta regulación es demasiada técnica y nos lleva a razonar y argumentar que cuando se verifica objetivamente una edificación terminada y/o concluida no es posible que el propietario (poseedor legítimo) pueda solicitar a su favor el mecanismo excepcional de la defensa extrajudicial de la posesión. Este razonamiento tiene sustento en que un poseedor precario no vive en un bien sin edificación o en proceso de edificación, así sea una covacha misera su "destino es albergar al hombre en el desarrollo de sus actividades", los que hemos visitado el medio rural conocemos de esa realidad; en consecuencia, si tratan de despojarme sin autorización de mi "albergue", podría hasta denunciar la comisión del delito de Contra el Patrimonio en su modalidad de Usurpación, generalmente cuando se trata de recuperar un bien de la posesión inmediata de un poseedor precario, necesito del apoyo de dos o más sujetos, tengo que utilizar algunos métodos que garanticen la eficacia de mi accionar, entre otros, estas conductas podrían ser consideradas como agravantes del tipo penal antes citado, hasta pondría en peligro la libertad personal. Considerando lo expuesto algún abogado dentro de su defensa técnica hasta podría argumentar que debe entenderse como edificación sólo cuando hay conformidad de obra expedido por la Municipalidad respectiva, entonces no existe delito por que el lugar que se ingreso simple y llanamente es una covacha, o tal vez argumente que debe entenderse como edificación sólo aquel bien cuya declaración de fábrica fue inscrita ante los Registros Públicos, u otro argumento destinado a resguardar el derecho a la libertad, en conclusión la falta de claridad de la norma pone en riesgo la libertad antes acotada; es más, algún profesional del derecho podría asesorar a su patrocinado que ingrese al bien a recuperar el mismo y que en éste no existe edificación alguna, pero con alguna interpretación en contra pondría en peligro la libertad de su patrocinado y tal vez su misma libertad. A fin de evitar los riesgos detallados $\mathrm{u}$ otros que podríamos imaginar, deberíamos tener un concepto más restringido, concreto y claro sobre que debemos entender como edificación, tal vez el concepto desarrollado por la Ley Nro. 29090, debería ser para actos administrativos, pero para actos de naturaleza civil y penal debería tenerse en cuenta un concepto más restringido.

c) ANÁLISIS DE LA TERCERA PARTE:

En el Perú estamos acostumbrado a dictar leyes que no tienen el carácter de preventivas, siempre son normas reactivas, tal vez este sea el 
Journal homepage: http://revistas.unap.edu.pe/rd/ E-mail: revistaderecho@unap.edu.pe

fracaso de nuestra normatividad, desde hace muchos años atrás, desde cuando tengo uso de razón, que se ha venido luchando contra el delito de tráfico ilícito de drogas, y una y otra vez se ha sancionado con las penas más graves, sin embargo, por el transcurso de a los años, ya estoy a punto de pasar a mejor vida, aún continuamos luchando contra este flagelo, eso me hace concluir que estamos equivocados en la forma como generamos nuestra normatividad.

El párrafo de la norma analizada a mi criterio fue hecha en un laboratorio y a espaldas de la realidad social, considerando que la norma regula que es posible recurrir a la Policía Nacional del Perú o a los Serenazgos de las Municipalidades a fin de que presten el apoyo necesario a efectos de garantizar el "estricto" cumplimiento de repeler la fuerza que se emplee contra el poseedor o el bien con la finalidad de poder recobrarlo, siempre y cuando sea despojado de su posesión, inclusive hace énfasis en que dicho cumplimiento es "bajo responsabilidad". En consecuencia, a fin de solicitar el apoyo de la Policía Nacional del Perú o a los Serenazgos de las municipalidades necesito llevar una carpeta en el que por lo menos contenga medios probatorios idóneos que acrediten mi posesión anterior al despojo, debe entenderse que no tiene interés si el solicitante tiene la calidad de poseedor legitimo o ilegitimo, para el primer caso debe tenerse en cuenta que debe presentarse el título de propiedad, de ser el caso la copia literal de la inscripción registral, en caso que no se encuentre inscrito deberá de presentarse el certificado negativo de búsqueda catastral (documentos que en la realidad demoran para su obtención no menos de 15 días), y, para el segundo caso me veré obligado a presentar los medios probatorios pertinentes que acreditan mi posesión, por ejemplo el título que acredita el traslado del derecho de posesión, certificaciones y constancias que acreditan mi posesión anterior y otros documentos; formada mi carpeta, debo entender, lo presento ante el Comisario de la Policía Nacional del Perú o el Jefe del Serenazgo de la Municipalidad, quien debe de verificar los mismos y determinar si es procedente o no el apoyo en la recuperación extrajudicial de la posesión por parte del personal a su cargo, aquí surge una primera interrogante ¿Quién es el Comisario de la Policía Nacional del Perú o el Jefe del Serenazgo para determinar un derecho preferente de posesión o propiedad?, lo peor podría ocurrir si se accede en forma positiva, entonces el personal policial o de Serenazgo se traslada al bien a fin de recuperar la posesión, y en ese accionar se presenta el poseedor inmediato quien presenta la documentación pertinente que acredita su derecho de posesión o de propiedad, hasta podrían ser falsos, otra vez surge la pregunta ¿Quién es el Comisario de la Policía Nacional del Perú o el Jefe del Serenazgo para determinar un derecho preferente de posesión o propiedad?

\section{d) ANÁliSIS DE LA CUARTA PARTE:}

El supuesto es que el propietario debe encontrarse bajo la posesión inmediata del bien, ejerciendo la misma como un poseedor legítimo, pues no resultaría razonable que un tercero arrebate con o sin justificación la posesión legitima de un bien, se trata de resguardar el derecho constitucional a la propiedad, sin embargo, la excepción es cuando ese tercero ya no tiene la calidad de poseedor por el contrario ostenta también el derecho de propiedad constituido a través de un proceso judicial, notarial o 
Journal homepage: http://revistas.unap.edu.pe/rd/ E-mail: revistaderecho@unap.edu.pe

administrativo de prescripción adquisitiva de dominio, debe entenderse que este nuevo derecho de propiedad subrogo al anterior derecho de propiedad, por las causales establecidas objetivamente en la ley.

Sin embargo, de una lectura fugaz y simple podría entenderse esta parte de la norma como que la defensa extrajudicial de la posesión no procede en contra de aquel que simple y llanamente ostenta el derecho de propiedad, este derecho constitucional tiene que estar aparejado por la posesión y no siempre ésta se ejerce de manera inmediata también se puede ejercer de manera mediata; en consecuencia, si el propietario es quien despojo de la posesión a un poseedor, éste último tiene derecho a solicitar y ejecutar la restitución de la posesión al amparo del artículo 920 del Código Civil, en este caso el propietario es considerado como un poseedor legítimo que arrebato el derecho de posesión a un poseedor ilegitimo (considerados en el artículo 906 y 911 del Código Civil), por tanto, puede hacer valer este derecho excepcional de defensa de la posesión.

Este último comentario es una interpretación forzada de la norma, tratando de darle sentido y utilidad práctica, pero dentro de un análisis ponderado, es inconcebible que dentro del rubro de defensa de la posesión se haya considerado una acción de defensa exclusiva del derecho de propiedad, este párrafo es patológico y contraviene la posesión como un derecho reconocido por la norma civil, una vez más, simple y llanamente me limito a comentar es terrible aprobar y tratar de hacer cumplir normas creadas a espaldas de la realidad social y con el objeto de asegurar algunos intereses que son negados.

\section{CONCLUSIONES:}

Podemos anotar las siguientes:

1. La posesión se materializa en la relación directa de los sujetos hacia los bienes la que es protegida por la legislación civil peruana;

2. Una forma de defensa de la posesión es la defensa extrajudicial de la posesión, regulada en el artículo 920 del Código Civil, la que fue modificada en la norma vigente de manera incoherente y a espaldas de la realidad social;

3. La regulación estipulada en el artículo 920 del Código Civil - Defensa Extrajudicial de la Posesión - es abstracta y oscura, confundiendo el derecho de defensa de la propiedad con la defensa de la posesión, es más, es incoherente regular en la misma actos en contra del poseedor como actos de defensa de la posesión;

4. El plazo de 15 días regulada en el artículo 920 del Código Civil genera una serie de interpretaciones, de acuerdo a la conducta desplegada por los sujetos determinados por los actos de posesión y desposesión;

5. Es necesario modificar el artículo 920 del Código Civil, como se tiene planteado, o en su caso convocar a un Pleno Casatorio Civil a fin de determinar la aplicabilidad de la norma en comento, no debiéndose olvidar que lo que debe regular es la defensa de la posesión exclusivamente. 
Journal homepage: http://revistas.unap.edu.pe/rd/ E-mail: revistaderecho@unap.edu.pe

\section{BIBLIOGRAFÍA:}

ALBALADEJO, Manuel. (1964). "Instituciones de Derecho Civil”. Barcelona. Editorial Bosch.

CUADROS VILLENA, Carlos Ferdinand. (1996). "Derechos Reales". Tomo IV. Editorial FECAT.

GONZALES LINARES, Nerio. (2012). "Derecho Civil Patrimonial: Derechos Reales". Lima. Jurista Editores.

GONZALES BARRON, Gunther Hernán. (2003). "Curso de Derechos Reales". Jurista Editores E.I.R.L.

GONZALES BARRON, Gunther Hernán. (2005). "Tratado de Derechos Reales". Lima. Jurista Editores.

RAMIREZ CRUZ, Eugenio María. (2017). "Tratado de Derechos Reales”. Tomo I, II y III. Cuarta Edición. Gaceta Jurídica.

LOPEZ SANTOS, Demetrio. (1990). "Derechos Reales". Editorial SIRSA.

VASQUEZ RÍOS, Alberto. (2014). "Derechos Reales". Tomo I y II. Editorial San Marcos. 